\title{
Potential impact of climate change on plant invasion in the Republic of Korea
}

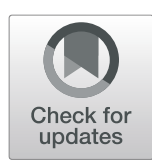

Pradeep Adhikari', Ja-Young Jeon ${ }^{1}$, Hyun Woo Kim ${ }^{1}$, Man-Seok Shin ${ }^{1}$, Prabhat Adhikari ${ }^{2}$ and Changwan Seo ${ }^{\text {* }}$

\begin{abstract}
Background: Invasive plant species are considered a major threat to biodiversity, ecosystem functioning, and human wellbeing worldwide. Climatically suitable ranges for invasive plant species are expected to expand due to future climate change. The identification of current invasions and potential range expansion of invasive plant species is required to plan for the management of these species. Here, we predicted climatically suitable habitats for 11 invasive plant species and calculated the potential species richness and their range expansions in different provinces of the Republic of Korea (ROK) under current and future climate change scenarios (RCP 4.5 and RCP 8.5) using the maximum entropy (MaxEnt) modeling approach.

Results: Based on the model predictions, areas of climatically suitable habitats for $90.9 \%$ of the invasive plant species are expected to retain current ecological niches and expand to include additional climatically suitable areas under future climate change scenarios. Species richness is predicted to be relatively high in the provinces of the western and southern regions (e.g., Jeollanam, Jeollabuk, and Chungcheongnam) under current climatic conditions. However, under future climates, richness in the provinces of the northern, eastern, and southeastern regions (e.g., Seoul, Incheon, Gyeonggi, Gyeongsangnam, Degue, Busan, and Ulsan) is estimated to increase up to 292\%, $390.75 \%$, and $468.06 \%$ by 2030,2050 , and 2080, respectively, compared with the current richness.

Conclusions: Our study revealed that the rates of introduction and dispersion of invasive plant species from the western and southern coasts are relatively high and are expanding across the ROK through different modes of dispersion. The negative impacts on biodiversity, ecosystem dynamics, and economy caused by invasive plant species will be high if preventive and eradication measures are not employed immediately. Thus, this study will be helpful to policymakers for the management of invasive plant species and the conservation of biodiversity.
\end{abstract}

Keywords: Climate change, Invasive plant species, Province, Species expansion, Species richness

\section{Background}

Invasive plant species are non-indigenous species that introduced into a new geographic region either deliberately or inadvertently and impacting negatively on agriculture, horticulture, and wild ecosystem (Cullen et al. 2011; Eminniyaz et al. 2013; Ricciardi 2013; Early et al. 2016). They alter the dynamics of plant communities and imperil the stability and functioning of ecosystem by affecting nutrient cycle, increasing soil acidity, competing with indigenous flora, and inhibiting their regeneration (Manchester and Bullock 2000; Ehrenfeld 2003; Hellmann et al. 2008; Bradley et al. 2010; Tiedeken and

\footnotetext{
* Correspondence: dharmascw@nie.re.kr

${ }^{1}$ National Institute of Ecology, 1210 Geumgang-ro, Maseo-myeon, Seocheon, Chungcheongnam 33657, Republic of Korea

Full list of author information is available at the end of the article
}

Stout 2015). The climate change exacerbates the threats and loss in ecosystem through various mechanisms including removal of climatic barriers and enhances to spread invasive species (Hellmann et al. 2008; Bradley et al. 2010). The invasive plant species have a higher tendency to shift their niche more rapidly compared to native species, and they are more likely to adapt in new environment (Hellman et al. 2008; Shrestha and Shrestha 2019). In addition, invasive plant species benefit from atmospheric carbon dioxide $\left(\mathrm{CO}_{2}\right)$ enrichment and global warming more than native plant species (Liu et al. 2017). Therefore, integrative study of climate change and biological invasion are required for long-term management of invasive plant species.

Globally, approximately 6500 invasive plant species are estimated to occur in terrestrial and aquatic ecosystems, and one sixth of the global land surface is highly vulnerable

(c) The Author(s). 2019 Open Access This article is distributed under the terms of the Creative Commons Attribution 4.0 International License (http://creativecommons.org/licenses/by/4.0/), which permits unrestricted use, distribution, and 
to invasion (Early et al. 2016). In the Republic of Korea (ROK), 14 species of plant species such as horseweed (Conyza canadensis), German evening primrose (Oenothera biennis), and tall fescue (Festuca arundinacea) are categorized as the invasive plant species and are considered as the ecologically aggressive species (National Institute of Ecology 2019).

Global climate change is considered to be a principle reason for spread of invasive species (Dullinger et al. 2017). Over the last century, the world has experienced a temperature rise of $0.78^{\circ} \mathrm{C}$, and the temperature is expected to rise $2.6-4.8^{\circ} \mathrm{C}$ by 2100 (IPCC 2013). In ROK, the rate of climate change has been predicted to be higher than the global climate change rates. The temperature increased $1.8^{\circ} \mathrm{C}$ over the last 100 years, and the average temperature is expected to increase by $0.63{ }^{\circ} \mathrm{C}$ every 10 years until 2100 and by $5.7^{\circ} \mathrm{C}$ by the end of this century (Ministry of Environment 2019). Thus, the potential for the spread of invasive plant species is thought to be high in ROK.

Ecological niche modeling is an empirical tool for simulating the spatial distributions of species, assessing the potential responses of organisms to climate change and resolving species niches based on environmental variables (Guillera-Arroita et al. 2015). Among the various ecological niche models (ENMs), the maximum entropy (MaxEnt) model is a widely used machine-learning technique that has high predictive accuracy while using a small set of data on species presence and environmental variables (Phillips et al. 2006; Koo et al. 2015; Dullinger et al. 2017; Lamsal et al. 2018; Thapa et al. 2018; Shrestha and Shrestha 2019).

Although many studies have addressed the ecology, distribution, and impact of climate change on invasive plant species distribution, most of studies to date have focused on either a handful of species or have been limited to a smaller geographical area of ROK (Cho and Lee 2015; Park and Kim 2015; Lee et al. 2016; Park et al. 2017; Ryu et al. 2017; Nam et al. 2018). Therefore, we predicted suitable habitat across the country for 11 invasive plant species, which are considered ecologically hazardous species in the ROK (Park and Kim 2015). Then, we calculated species richness and species expansion of invasive plant species in different provinces of the ROK to assess the potential for invasion in different provinces of the ROK and to develop a theoretical reference framework for management plans to combat the potential spread of invasive plant species.

\section{Methods}

\section{Study area}

This study was conducted in all provinces and islands of the ROK (Fig. 1), covering approximately $45.72 \%$ of the total landmass of the Korean Peninsula. Geographically, the terrain of the ROK is mostly mountainous in the northern and eastern parts of the country and contains lowland and flat plains in the southern and western regions. The climate of the ROK is categorized into warmtemperate, temperate, and cold-temperate. The southern coast and islands experience a warm-temperate climate, the central and northern parts of the ROK are temperate, and the high mountains have a cold-temperate climate. The southern region is relatively warm and wet, whereas the northern region is cold and continental. The annual precipitation $(\sim 1200 \mathrm{~mm})$ is high in summer and low in winter, with snow deposition in the mountains. The vegetation of the ROK is categorized as deciduous broadleaf, temperate broadleaf, coniferous, subalpine, and alpine, and the overall biodiversity of the ROK includes 41,483 recorded species including 5308 plants, 1899 vertebrates, and 22,612 invertebrate (Ministry of Environment 2014).

\section{Species presence data}

The 11 most problematic invasive plant species in the ROK, based on their rapid expansion and adverse impacts on terrestrial ecosystems (Park and Kim 2015), were selected for distribution modeling (Table 1). Species occurrence data were obtained from field surveys and secondary sources (National Institute of Environmental Research 2013; National Institute of Ecology 2017). At least 10 presence points were used for each invasive plant species to obtain accurate model performance. Random points were chosen using a raster map of the ROK with ArcGIS 10.3 (ESRI, Redlands, CA, USA).

\section{Environmental variables}

Nineteen bioclimatic variables (Additional file 1: Table S1) were considered to be important for the distribution of invasive plant species. Monthly temperature (minimum and maximum) and precipitation data were obtained from the Korea Meteorological Administration for the estimation of current and future climates of the ROK. The HedGEM3-RA global circulation model was used to predict the future climate change scenarios RCP 4.5 and RCP 8.5 using Package Dismo in R (Robert et al. 2017). The current climate conditions were determined by averaging the data from 1950 to 2000 . Similarly, the future climate conditions in 2050 and 2070 were estimated from the period of 2046 to 2055 and 2066 to 2075, respectively, similar to Adhikari et al. (2018). In all climatic data, the spatial resolution was $0.01^{\circ}(36 \mathrm{~s})$ and approximately $1 \mathrm{~km}^{2}$.

\section{Model development, evaluation, and validation}

The MaxEnt Package 1.3.3 for R (https://cran.r-project.org/ web/packages/maxent) was used to predict the current and future distributions of invasive plant species in different 


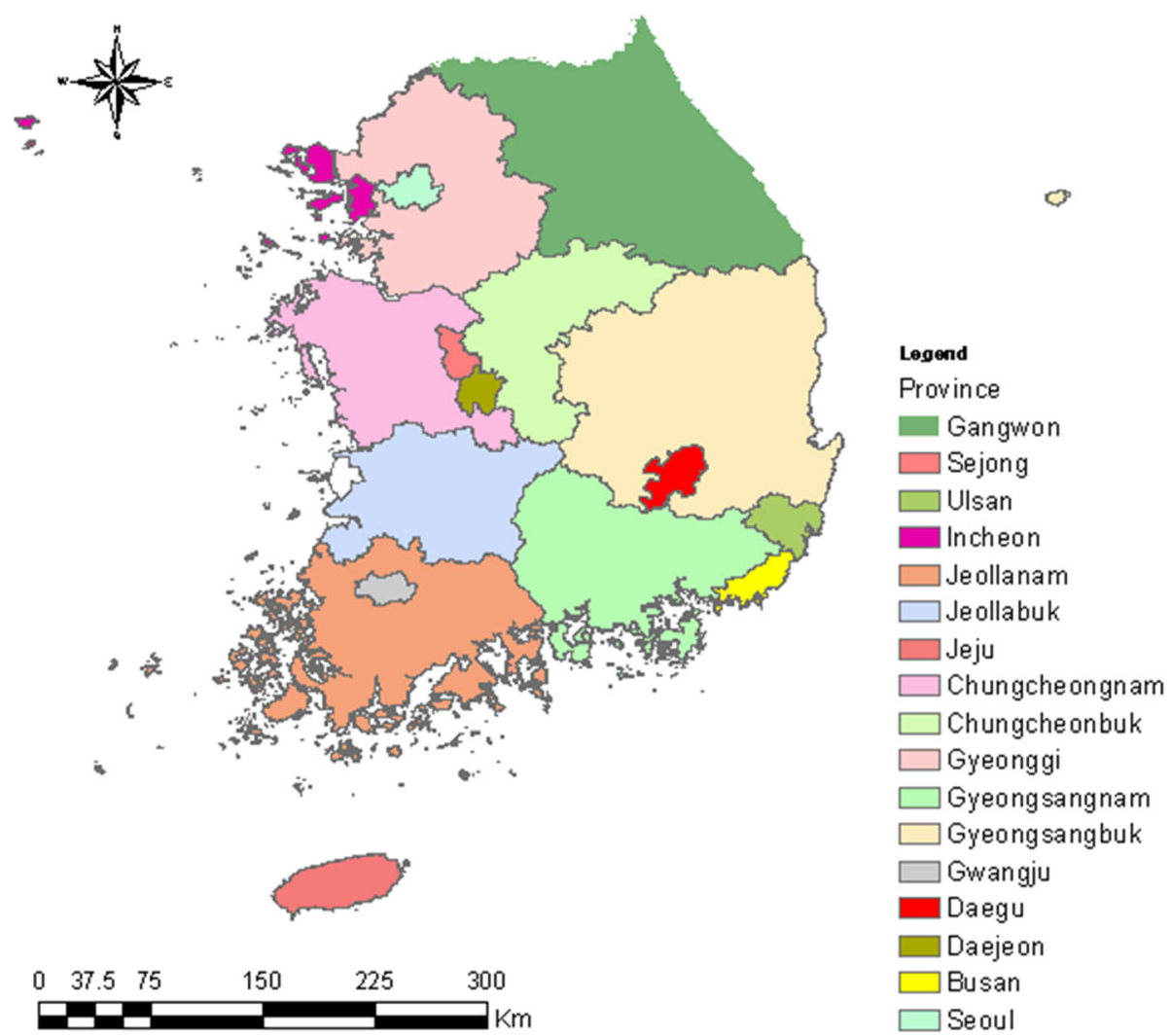

Fig. 1 Provinces of Republic of Korea. Each province is indicated by different color and the name of the provinces are given in legend

provinces of the ROK similar to Bezeng et al. (2017), Lamsal et al. (2018), Manzoor et al. (2018), and Thapa et al. (2018). These measurements were achieved from the random split of the data into model calibration and model validation sets at the ratio of $75: 25$. Accuracy prediction and validation of each model were assessed based on the area under the receiver operator characteristic (ROC) curve (AUC) (Pearsons 2010) and the True Skill Statistic (TSS) (Allouche et al. 2006; Shabani et al. 2018) The AUC, ranging from 0 to 1 , acts as a threshold-

Table 1 List of invasive plant species used in species distribution models

\begin{tabular}{|c|c|c|c|c|c|c|c|}
\hline $\begin{array}{l}\text { Plant id } \\
\text { no. }\end{array}$ & Common name & Species name & $\begin{array}{l}\text { Native } \\
\text { range }\end{array}$ & Mode of introduction & $\begin{array}{l}\text { First record in } \\
\text { Korea }\end{array}$ & $\begin{array}{l}\text { AUC } \\
\text { value }\end{array}$ & $\begin{array}{l}\text { TSS } \\
\text { value }\end{array}$ \\
\hline S407b & $\begin{array}{l}\text { Common } \\
\text { ragweed }\end{array}$ & Ambrosia artemisiifolia & $\mathrm{nAm}$ & Unintentional & 1963 & 0.734 & 0.641 \\
\hline S408b & Giant ragweed & Ambrosia trifida & $\mathrm{nAm}$ & Unintentional & 1974 & 0.915 & 0.878 \\
\hline$S 409 b$ & White snakeroot & Ageratina altissima & $\mathrm{nAm}$ & Unintentional & 1980 & 0.958 & 0.779 \\
\hline S410b & Knotgrass & $\begin{array}{l}\text { Paspalum distichum var. } \\
\text { indutum }\end{array}$ & $\mathrm{nAm}$ & Unintentional & 1994 & 0.967 & 0.805 \\
\hline S411b & Knotgrass & Paspalum distichum & nAm & Unintentional & 1964 & 0.792 & 0.800 \\
\hline$S 412 b$ & Horse nettle & Solanum carolinense & $\mathrm{nAm}$ & Unintentional & 1980 & 0.858 & 0.677 \\
\hline S413b & Red sorrel & Rumex acetosella & Eu-As & Unintentional & 1949 & 0.798 & 0.635 \\
\hline S414b & Bur cucumber & Sicyos angulatus & $\mathrm{nAm}$ & Unintentional & 1994 & 0.924 & 0.789 \\
\hline S415b & Cat sear & Hypochaeris radicata & $\mathrm{Eu}$ & Unintentional & 1992 & 0.976 & 0.876 \\
\hline $\mathrm{S} 417 \mathrm{~b}$ & Tall golden red & Solidago altissima & $\mathrm{nAm}$ & $\begin{array}{l}\text { Intentional (nectar } \\
\text { source) }\end{array}$ & 1980 & 0.886 & 0.892 \\
\hline S418b & Milk thistle & Lactuca serriola & Eu-As-nAf & Unintentional & 1980 & 0.896 & 0.868 \\
\hline
\end{tabular}

nAm North America, Eu Europe, As Australia, nAf North Africa (source: Jung et al. 2017; National Institute of Ecology 2019) 
independent approach to distinguish presence from absence to evaluate model performance (Thuiller et al. 2005). Model performance was categorized as failed (0.5-0.6), poor (0.6-0.7), fair (0.7-0.8), good (0.8-0.9), and excellent (0.9-1), while validating the model results (Swets 1988). The TSS accounts for both specificity and sensitivity and ranges between -1 and +1 , indicating an agreement no better than random and a perfect agreement between observation and prediction, respectively (Allouche et al. 2006; Lobo et al. 2008; Koo et al. 2015).

\section{Suitable habitat, species richness, and species expansion} Area of suitable habitat for each invasive plant species under the climate change scenarios RCP 4.5 and RCP 8.5 was calculated for the years 2030, 2050, and 2080. The distribution maps of all invasive plant species (Additional file 2) were summed to obtain the current and potential species richness maps. A shapefile of the 17 provinces of the ROK was overlaid on the species richness maps, and average species richness and maximum species richness were extracted using the zonal statistics of the spatial analyst tool in ArcGIS 10.3 (ESRI, Redlands, CA, USA).

Invasive plant species expansion was determined by differentiating between current habitat and future habitat of each invasive plant species and reclassifying them based on the potentially new habitat expansion compared to the current distribution. The habitat expansions of all species were overlaid to produce the potential habitat expansion maps of invasive plant species in different provinces of the ROK. The whole process was performed with R software (https://www.r-project.org).

\section{Results}

Variable selection and contributions to models

We performed Pearson's correlation analysis of the 19 bioclimatic variables (Additional file 1: Table S1) and selected six variables: annual mean temperature (Bio1), mean diurnal temperature range (Bio2), isothermality (Bio3), annual precipitation (Bio12), precipitation of the wettest month (Bio13), and precipitation of the driest month (Bio14). All of these variables are weakly correlated with each other, but they have strong correlations $(r<$ 0.99) with other variables such as Bio4, Bio5, Bio6, and Bio19 (Additional file 1: Table S2). The threshold for weak correlation was $r<0.5$. Thus, these six variables were used in the MaxEnt models for studying the distributions of invasive plant species.

The bioclimatic variable with the greatest model contribution differed among species (Table 2). Bio3 had the highest contributions (27.51-41.09\%) to the modeling of six species (such as Ageratina altissima and Solanum carolinense), and Bio 14 contributed the highest proportion to the Ambrosia artemisiifolia (38.17\%), Hypochaeris radicata (77.02\%), and Rumex acetosella (24.41\%). Similarly, Bio1 and Bio2 exhibited the highest contributions to the Paspalum distichum var. indutum (32.39\%) and Paspalum distichum (30.36\%), respectively. In this study, the temperaturerelated variable isothermality was a dominant driving factor for the ENMs of many invasive plant species.

\section{Model evaluation and validation}

Altogether, 11 invasive plant species were used in this study (Table 1), and independent ENMs were established for predicting current and future distributions of each species. We used both AUC and TSS values to evaluate model performance (Table 1). The mean AUC value of 11 invasive plant species was 0.808 , ranging from 0.734 to 0.976 , and the mean TSS value was 0.774 , ranging between 0.641 and 0.892 . Based on the evaluation, five species showed excellent (e.g., A. altissima), three species showed good (e.g., S. carolinense), and remaining three species showed fair (e.g., A. artemisiifolia) model performance.

Table 2 Contribution of bioclimatic variables to models

\begin{tabular}{|c|c|c|c|c|c|c|}
\hline Name of species & Bio1 & $\mathrm{Bio} 2$ & Bio3 & Bio12 & Bio13 & Bio14 \\
\hline Ambrosia artemisiifolia & 13.96 & 10.52 & 17.65 & 11.90 & 7.79 & 38.17 \\
\hline Ambrosia trifida & 23.86 & 10.67 & 27.51 & 14.29 & 13.03 & 10.65 \\
\hline Ageratina altissima & 15.75 & 10.70 & 41.09 & 5.28 & 22.67 & 4.50 \\
\hline Paspalum distichum var. indutum & 32.39 & 15.59 & 14.22 & 13.36 & 9.98 & 14.45 \\
\hline Paspalum distichum & 27.84 & 30.36 & 21.93 & 13.00 & 1.29 & 5.59 \\
\hline Solanum carolinense & 18.62 & 17.96 & 28.44 & 20.32 & 8.41 & 6.26 \\
\hline Rumex acetosella & 20.09 & 10.94 & 19.95 & 19.82 & 4.79 & 24.41 \\
\hline Sicyos angulatus & 17.91 & 15.30 & 28.27 & 12.88 & 15.22 & 10.41 \\
\hline Hypochaeris radicata & 5.09 & 5.66 & 4.75 & 5.37 & 2.12 & 77.02 \\
\hline Solidago altissima & 17.95 & 23.73 & 28.05 & 15.14 & 6.48 & 8.66 \\
\hline Lactuca serriola & 19.14 & 18.69 & 32.76 & 10.46 & 9.34 & 9.62 \\
\hline
\end{tabular}




\section{Prediction of suitable habitats}

The extents of climatically suitable habitats for the 11 invasive plant species were modeled to show the distribution of each species and the calculated area of the potential habitats under current and future climate change scenarios (Table 3). Under current climatic conditions, A. artemisiifolia had the highest suitable area $\left(44,954 \mathrm{~km}^{2}\right)$, while H. radicata had the least area of suitable habitat (3768 $\mathrm{km}^{2}$ ). Under future climatic conditions, Solidago altissima would have the highest suitable area, and $P$. distichum would have the least area of suitable habitat by 2030, 2050, and 2080 under the RCP 4.5 (Table 3). We calculated the area of new habitat expansion for each invasive plant species separately, which indicated that expansion of suitable area will be greatest by 2030 for Lactuca serriola, but by 2050 and 2080, P. distichum var. indutum will have greatest suitable area under the RCP 4.5 (Table 4). Although estimated rates and trends of expansion were not consistent, the suitable area for invasive plant species is predicted to expand continuously, except for the suitable area for P. distichum.

\section{Current species richness of invasive plant species}

The potential species richness of invasive plant species under current climatic conditions is presented in Fig. 2 and Table 5. The provinces located in the western (Jeollabuk, Daejeon, Sejong, Chungcheongnam, and Gwangju) and southern (Jeollanam and Jeju) regions showed pronounced species richness, estimated to be average species richness 4.38-5.81 and maximum species richness 9-11. However, the provinces in the northeastern (Gangwon), southeastern (Gyeongsangnam, Ulsan, Busan), eastern (Gyeongsangbuk and Daegu), and central (Chungcheongbuk) regions have relatively low species richness, averaging 1.19-2.05, with maximum species richness predicted to range from 5 to 7 .

\section{Future species richness of invasive plant species}

The potential richness of invasive plant species in different provinces of the ROK was predicted to increase by 2030, 2050, and 2080 under the climate change scenarios RCP 4.5 and RCP 8.5 (Fig. 3 and Table 5). The estimated average and maximum species richness by 2030, 2050, and 2080 are highest in Seoul and lowest in Gangwon under the RCP 4.5 .

The predicted rates of increasing average species richness are inconsistent among the provinces. The provinces in the northern (Seoul, Gyeonggi, Incheon), eastern, and southeastern regions are predicted to have relatively high rates of increase in average species richness in the future compared to the provinces in the western and southern regions (Jeollanam), where species richness is estimated to increase $17.8-292 \%$ by $2030,25.75-390.75 \%$ by 2050 , and $59.15-468.06 \%$ by 2080 under the RCP 4.5 compared with the current richness.

Maximum species richness is not predicted to increase in as large as a proportion similar to average species richness in all provinces. The provinces of Seoul, Incheon, Gyeonggi, Chungcheongbuk, Daegu, Gyeongsangbuk, Gangwon, Gyeongsangnam, Busan, and Ulsan have predicted maximum species richness values of $7-9$ by $2030,9-11$ by 2050 , and $10-11$ by 2080 under the RCP 4.5 (Table 5). The other provinces show very similar estimations of maximum species richness.

\section{Invasive plant species expansion}

The invasive plant species expansion in different provinces of the ROK is shown in Fig. 4 and Table 6. The

Table 3 Suitable habitat for invasive species $\left(\mathrm{km}^{2}\right)$ under current and future climate conditions

\begin{tabular}{|c|c|c|c|c|c|c|c|}
\hline \multirow[t]{2}{*}{ Species name } & \multirow[t]{2}{*}{ Current } & \multicolumn{3}{|l|}{$\mathrm{RCP} 4.5$} & \multicolumn{3}{|l|}{$\mathrm{RCP} 8.5$} \\
\hline & & 2030 & 2050 & 2080 & 2030 & 2050 & 2080 \\
\hline Ambrosia artemisiifolia & 44,954 & 27,913 & 40,547 & 58,969 & 46,474 & 41,794 & 29,007 \\
\hline Ambrosia trifida & 22,979 & 12,469 & 27,587 & 54,389 & 30,189 & 22,320 & 34,129 \\
\hline Ageratina altissima & 9360 & 11,508 & 40,612 & 63,969 & 30,732 & 29,428 & 34,588 \\
\hline Paspalum distichum var. indutum & 7394 & 39,395 & 57,726 & 90,165 & 57,311 & 56,861 & 93,734 \\
\hline Paspalum distichum & 34,173 & 8292 & 8662 & 1479 & 8257 & 11,911 & 8949 \\
\hline Solanum carolinense & 28,886 & 23,557 & 27,634 & 53,539 & 38,775 & 18,630 & 26,238 \\
\hline Rumex acetosella & 31,035 & 38,301 & 51,458 & 81,550 & 59,669 & 31,844 & 55,060 \\
\hline Sicyos angulatus & 10,669 & 8345 & 14,794 & 39,642 & 21,524 & 21,272 & 27,540 \\
\hline Hypochaeris radicata & 3768 & 28,605 & 30,777 & 40,272 & 26,916 & 26,932 & 73,936 \\
\hline Solidago altissima & 12,375 & 46,258 & 61,366 & 85,241 & 59,949 & 70,068 & 87,678 \\
\hline Lactuca serriola & 16,265 & 41,698 & 46,152 & 74,858 & 48,243 & 52,460 & 82,309 \\
\hline Total area of ROK $\left(\mathrm{km}^{2}\right)$ & $100,411.36^{a}$ & & & & & & \\
\hline
\end{tabular}

${ }^{a}$ Source: Ministry of Land Infrastructure and Transport, Republic of Korea 2018 
Table 4 Habitat expansion of invasive species $\left(\mathrm{km}^{2}\right)$ under the future climate change scenarios

\begin{tabular}{|c|c|c|c|c|c|c|}
\hline \multirow[t]{2}{*}{ Name of invasive species } & \multicolumn{3}{|l|}{ RCP 4.5} & \multicolumn{3}{|l|}{ RCP 8.5} \\
\hline & 2030 & 2050 & 2080 & 2030 & 2050 & 2080 \\
\hline Ambrosia artemisiifolia & 10,699 & 18,772 & 28,270 & 21,189 & 20,673 & 15,340 \\
\hline Ambrosia trifida & 5132 & 16,234 & 33,949 & 16,210 & 13,583 & 17,875 \\
\hline Ageratina altissima & 7622 & 31,144 & 54,186 & 22,763 & 22,322 & 26,287 \\
\hline Paspalum distichum var. indutum & 31,999 & 49,756 & 81,639 & 50,047 & 48,729 & 85,165 \\
\hline Paspalum distichum & 1515 & 642 & 0 & 788 & 3036 & 369 \\
\hline Solanum carolinense & 7904 & 7923 & 29,758 & 13,210 & 5342 & 20,772 \\
\hline Rumex acetosella & 19,286 & 23,950 & 51,502 & 32,461 & 14,204 & 41,226 \\
\hline Sicyos angulatus & 7901 & 11,756 & 31,253 & 18,771 & 18,494 & 22,918 \\
\hline Hypochaeris radicata & 25,523 & 27,385 & 35,882 & 23,847 & 23,067 & 69,018 \\
\hline Solidago altissima & 33,312 & 47,988 & 71,753 & 46,845 & 56,701 & 75,479 \\
\hline Lactuca serriola & 34,638 & 32,878 & 58,113 & 38,405 & 40,331 & 65,176 \\
\hline
\end{tabular}

average species expansion is predicted to be highest by 2030, 2050, and 2080 in Seoul under RCP 4.5. Under the extreme climate change scenario (RCP 8.5), the maximum species expansion would be highest in Seoul by 2030 (11 species), Ulsan and Busan by 2050 (11 species), and Gangwon, Gyeonggi and Gyeongsangbuk by 2080 (11 species). These results indicate that the provinces in the northern and eastern regions of the ROK will have the highest species richness of invasive plant species in the future.

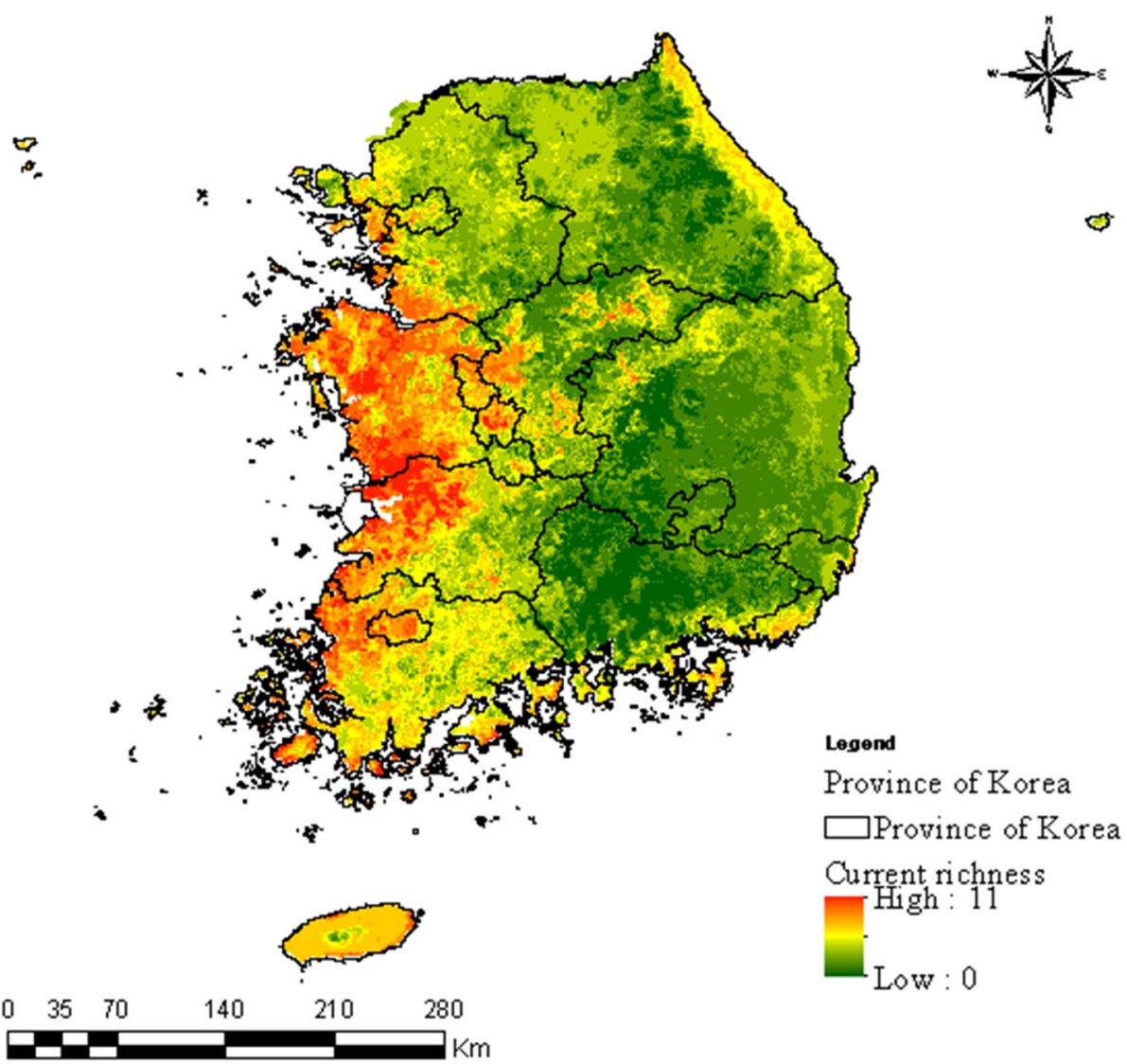

Fig. 2 Potential species richness of invasive plant species under the current climatic condition. The black lines on the map showing 17 provinces of Republic of Korea 
Table 5 Average and maximum invasive species richness in different provinces of Korea

\begin{tabular}{|c|c|c|c|c|c|c|c|c|c|c|c|c|c|c|}
\hline \multirow[t]{3}{*}{ Province name } & \multirow{2}{*}{\multicolumn{2}{|c|}{ Current }} & \multicolumn{6}{|c|}{ RCP 4.5} & \multicolumn{6}{|c|}{ RCP 8.5} \\
\hline & & & \multicolumn{2}{|l|}{2030} & \multicolumn{2}{|l|}{2050} & \multicolumn{2}{|l|}{2080} & \multicolumn{2}{|l|}{2030} & \multicolumn{2}{|l|}{2050} & \multicolumn{2}{|l|}{2080} \\
\hline & $\overline{A v g}$ & Max & Avg & $\operatorname{Max}$ & Avg & $\operatorname{Max}$ & $\overline{A v g}$ & $\operatorname{Max}$ & $\overline{\text { Avg }}$ & $\operatorname{Max}$ & $\overline{A v g}$ & $\operatorname{Max}$ & Avg & Max \\
\hline Gangwon & 2.05 & 7.00 & 2.07 & 6.00 & 2.45 & 9.00 & 4.41 & 10.00 & 4.02 & 10.00 & 3.63 & 11.00 & 6.89 & 11.00 \\
\hline Gyeonggi & 2.98 & 8.00 & 3.51 & 10.00 & 6.83 & 11.00 & 9.56 & 11.00 & 7.35 & 11.00 & 6.78 & 10.00 & 9.00 & 11.00 \\
\hline Gyeongsangnam & 1.19 & 8.00 & 4.67 & 10.00 & 5.84 & 11.00 & 6.76 & 11.00 & 5.52 & 11.00 & 4.82 & 11.00 & 5.31 & 11.00 \\
\hline Gyeongsangbuk & 1.53 & 7.00 & 2.35 & 10.00 & 2.56 & 9.00 & 4.93 & 11.00 & 1.79 & 11.00 & 2.78 & 11.00 & 4.96 & 11.00 \\
\hline Gwangju & 5.80 & 9.00 & 5.98 & 9.00 & 7.51 & 11.00 & 5.58 & 9.00 & 5.78 & 8.00 & 4.60 & 8.00 & 4.80 & 9.00 \\
\hline Daegu & 1.31 & 5.00 & 3.95 & 8.00 & 2.89 & 9.00 & 5.70 & 11.00 & 3.83 & 10.00 & 3.46 & 9.00 & 5.12 & 10.00 \\
\hline Daejeon & 5.03 & 9.00 & 4.20 & 10.00 & 5.99 & 9.00 & 10.09 & 11.00 & 7.01 & 9.00 & 5.60 & 10.00 & 5.51 & 10.00 \\
\hline Busan & 3.60 & 7.00 & 6.50 & 10.00 & 8.72 & 11.00 & 9.30 & 11.00 & 7.19 & 11.00 & 7.36 & 11.00 & 5.86 & 8.00 \\
\hline Seoul & 3.31 & 8.00 & 6.98 & 11.00 & 8.84 & 11.00 & 9.80 & 11.00 & 8.38 & 11.00 & 8.86 & 11.00 & 9.18 & 11.00 \\
\hline Sejong & 5.32 & 9.00 & 2.52 & 7.00 & 5.00 & 9.00 & 8.51 & 10.00 & 2.87 & 9.00 & 2.88 & 6.00 & 5.24 & 9.00 \\
\hline Ulsan & 1.87 & 6.00 & 5.50 & 9.00 & 5.76 & 11.00 & 6.30 & 10.00 & 5.60 & 11.00 & 5.76 & 11.00 & 4.67 & 8.00 \\
\hline Incheon & 4.31 & 8.00 & 5.64 & 10.00 & 6.44 & 11.00 & 9.00 & 11.00 & 5.57 & 11.00 & 4.05 & 8.00 & 8.12 & 10.00 \\
\hline Jeollanam & 4.38 & 9.00 & 5.14 & 10.00 & 6.77 & 11.00 & 6.26 & 11.00 & 6.51 & 11.00 & 5.70 & 11.00 & 5.75 & 11.00 \\
\hline Jeollabuk & 4.47 & 11.00 & 3.69 & 10.00 & 6.35 & 11.00 & 8.31 & 11.00 & 5.28 & 10.00 & 4.64 & 11.00 & 5.47 & 11.00 \\
\hline Jeju & 4.97 & 9.00 & 6.67 & 11.00 & 6.25 & 11.00 & 7.91 & 11.00 & 5.92 & 9.00 & 6.32 & 11.00 & 6.37 & 11.00 \\
\hline Chungcheongnam & 5.81 & 10.00 & 3.30 & 10.00 & 5.62 & 11.00 & 8.61 & 11.00 & 4.40 & 10.00 & 4.53 & 11.00 & 6.49 & 11.00 \\
\hline Chungcheongbuk & 2.64 & 8.00 & 1.78 & 8.00 & 3.11 & 8.00 & 8.32 & 11.00 & 4.61 & 10.00 & 3.16 & 9.00 & 6.12 & 11.00 \\
\hline
\end{tabular}

Avg average species richness, Max maximum species richness

\section{Discussion}

This study estimated current potential and future predicted habitat of the most troublesome invasive plant species in the ROK (11 species) in different provinces. The performance of the ENMs should not be altered by prevalence (data size), but there should be an integration of both omission and commission errors (Allouche et al. 2006). The AUC value is independent of the prevalence. However, this index is sometimes criticized because it equally weights the commission and omission errors and avoids real prediction (Lobo et al. 2008). Therefore, we applied both AUC and TSS values to evaluate the model performance. The mean value of AUC shows that the model performance was very good, demonstrating good prediction results (Swets 1988). Furthermore, the mean value of TSS reveals that there was a good agreement between observations and predictions of the MaxEnt model (Allouche et al. 2006).

Climate change facilitates the introduction, dispersion, and naturalization of invasive and alien species and also reduces the resilience of aquatic and wild ecosystems to invasive species (Hellmann et al. 2008). Our model predicted that all the invasive plant species will retain their current ecological niches while adding areas of climatically suitable habitats in the ROK in the future, as concluded by Lamsal et al. (2018) and Shrestha and Shrestha (2019). However, the rates and extents of the climatically suitable habitats were not predicted to be consistent among all species. In this study, A. altissima, $H$. radicata, $P$. distichum var. indutum, S. altissima, and L. serriola are predicted to show unusual rates of habitat expansion (Additional file 2: Figure S3, Figure S5, Figure S9-S11), estimated at $156.36-659.15 \%$ by $2030,183.75-$ $716.79 \%$ by 2050 , and $360.23-968.78 \%$ by 2080 relative to the current climatically suitable habitat similar to Cho and Lee (2015) and Nam et al. (2018). The change in the suitability of habitats for invasive plant species depends not only on the climatic variables related to precipitation and temperature used in the MaxEnt model but also on different kinds of non-climatic factors, such as land topography, altitude, and latitude, and on each individual plant's physiological and morphological advancement and ability to cope with an adverse climate (Lamsal et al. 2018). Therefore, the climatically suitable habitat for each species could be different under the same climatic conditions in the future. Climate change may limit the invasiveness of some species, creating opportunities for ecosystem restoration (Manzoor et al. 2018). We predict a decrease in the climatically suitable habitat for $P$. distichum in the future (Additional file 2: Figure S5), and no more suitable habitat expansion will occur by 2080 under RCP 4.5 (Table 4). In this study, three temperature-related variables (Bio1, Bio2, and Bio3) have found high contribution in its model that suggests increase in temperature is unfavorable to its life cycle. Lee et al. (2016) mentioned that the temperature above $20^{\circ} \mathrm{C}$ is harmful for the 


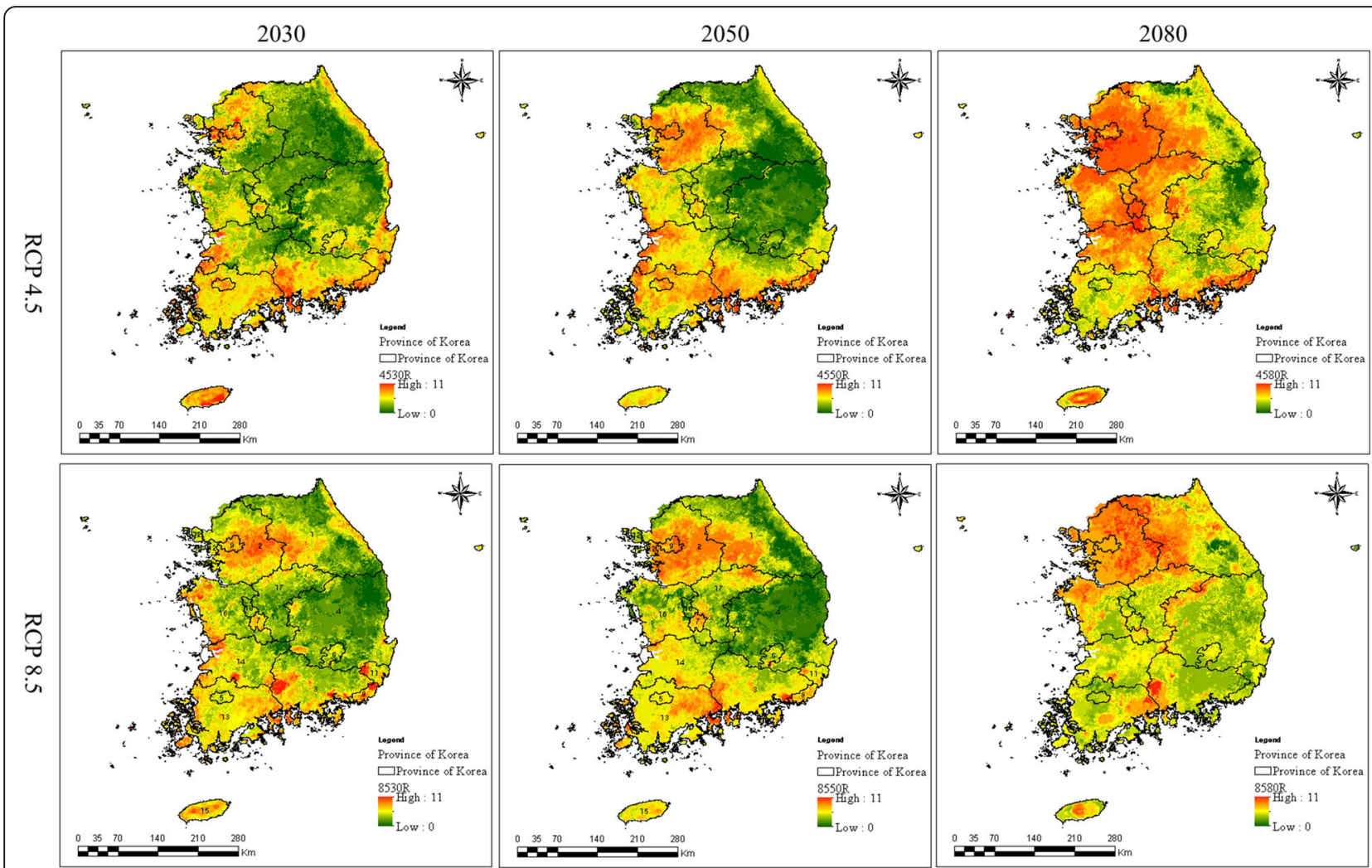

Fig. 3 Potential species richness of invasive plant species under the climate change scenarios RCP 4.5 and RCP 8.5 by the years 2030, 2050, and 2080. The black lines on the map showing 17 provinces of Republic of Korea

germination of $P$. distichum and concluded that the temperature-related variables such as annual mean temperature are critical factors in determining its distribution.

Under the current climate, the average and maximum species richness was estimated to be relatively high in Jeollanam, Jeollabuk, Chungcheongnam, Daejeon, and Gwangju compared to other provinces. Currently, 7-8 invasive plant species, e.g., A. artemisiifolia, $P$. distichum, $P$. distichum var. indutum, and $R$. acetosella are densely distributed in such provinces. However, the other provinces adjoining the sea, e.g., Incheon, Seoul, Gyeongsangnam, Gyeongsangbuk, Ulsan, Busan, and Gangwon, are predicted to be invaded by $5-7$ species. In these provinces, invasion is predicted to be concentrated on islands and in coastal areas of the mainland. This result indicates that introduction and dispersion of invasive plant species is relatively high in the ROK from the western and southern coast. Invasion typically occurs during foreign trade and tourism, and in particular, invasive species enter through ports (Hellmann et al. 2008). In the ROK, altogether, 18 international ports of different sizes, e.g., Incheon, Pyeongtaek, Gunsan, Masan, Yeosu, Mokpo, Busan, and Ulsan, exist in various provinces for foreign trade. Invasive species may be introduced to the
ROK through these ports either purposely or inadvertently and colonize wild and urban ecosystems of the adjacent provinces (Early et al. 2016), then dispersed across the ROK through various modes of dispersion and human transportation systems, such as road and railway connections, as suggested by Eminniyaz et al. (2013).

Globally, climate change induces habitat expansion of invasive species northward (Petitpierre et al. 2016). In this study, we also predicted range expansion of invasive plant species in the northern and northeastern regions, particularly in Chungcheongbuk, Gyeonggi, Seoul, Incheon, Gyeongsangbuk, and Gangwon and in Jeollabuk, Jeollanam, Chungcheongnam, Gyeongsangnam, Busan, and Ulsan. In Jeju, we estimated habitat expansion of invasive plant species at high elevation near Halla Mountain $(1950 \mathrm{~m})$ from the coastal region. These results show that climate change causes expansion of habitat of invasive plant species towards high latitudes $\left(>36^{\circ}\right.$ $\mathrm{N}$ ) and high elevation (not calculated in scale) in the ROK by removing current climatic barriers and shifting habitats to higher latitudes and elevations (Hellmann et al. 2008). Consistent with our findings, many studies have predicted the expansion of distribution ranges of invasive plants species towards higher latitudes and elevations in response to climate change (Loarie et al. 2008; 


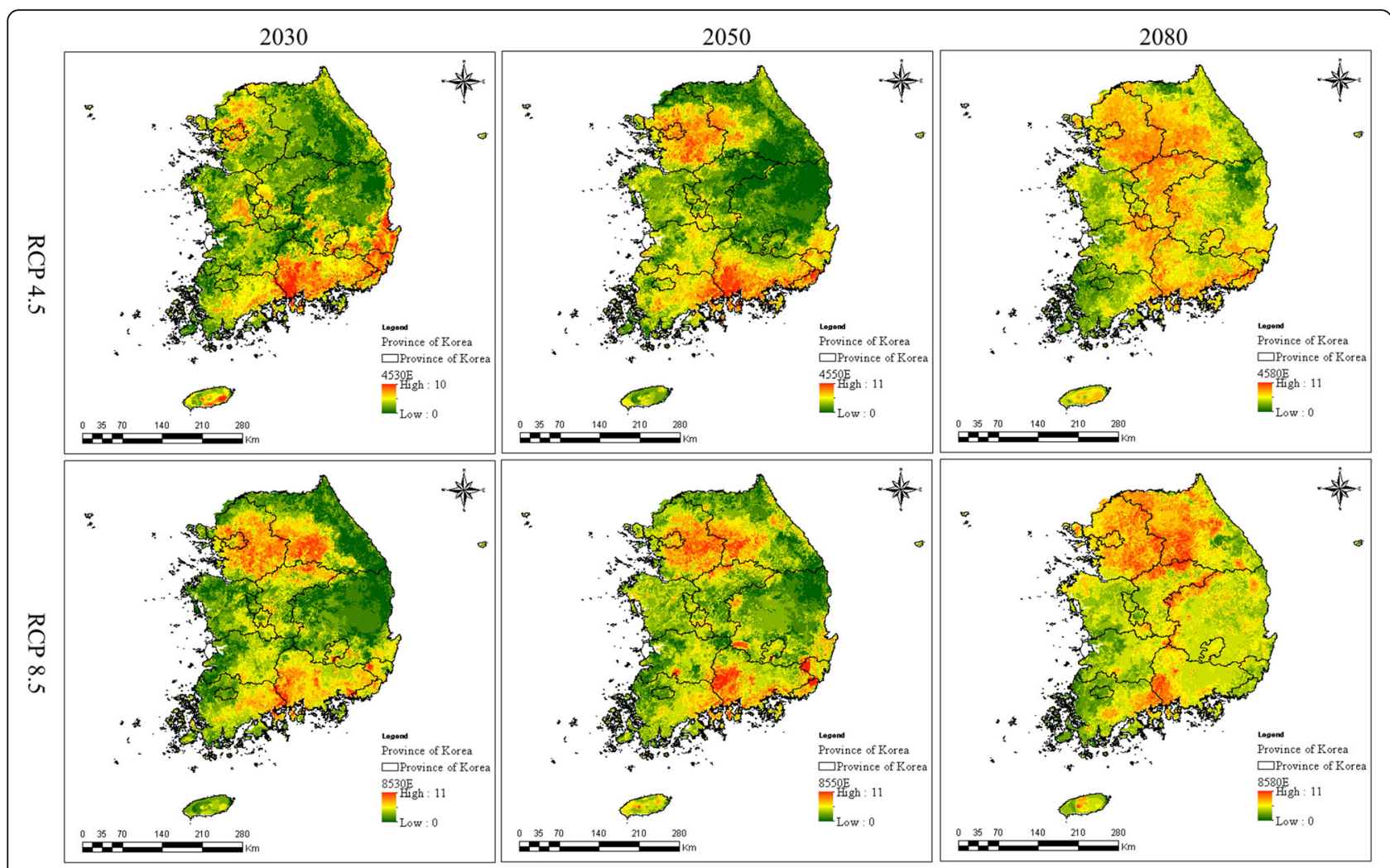

Fig. 4 Potential species expansion of invasive plant species under the climate change scenarios RCP 4.5 and RCP 8.5 by the years 2030, 2050, and 2080. The black lines on the map showing 17 provinces of Republic of Korea

Lenoir et al. 2008; Bradley et al. 2012; Shrestha and Shrestha 2019).

All the studied invasive plant species were introduced to the ROK either intentionally or unintentionally (Table 1). The S. altissima is native to North America and was introduced to the ROK before 1980 for nectar purpose (Jung et al. 2017). It is distributed across the ROK and is invading the forests. The other plant species, A. artemisiifolia, Ageratina altissima, P. distichum, $R$. acetosella, and $L$. serriola were accidently introduced to the ROK, as recorded between 1932 and 1994 (National Institute of Ecology 2019). Although some invasive plant species such as $P$. distichum could be food resource to wild herbivores, e.g., roe deer (Adhikari et al. 2016), they have poor nutrition value. Most of the invasive plant species originated from the American continents, followed by Eurasia, Europe, and Africa, and may have been introduced to the ROK via trade, tourism, and tidal activity of the sea. The invasive plant species native to tropical countries have much higher critical thermal maxima than do native species, indicating that they can thrive in higher temperatures and could be dominant to native species under climate change conditions. Additionally, invasive species have some important characteristics, such as short reproduction times, high fecundity, strong dispersal ability, and high environmental tolerance, that help them establish well in new environments (Bradley et al. 2010). Along with climate change, several non-climatic components, including anthropogenic activities such as rapid land use and land cover change, road construction, urban development, foreign trade, agriculture, and tourism, promote invasion (Martin et al. 2013).

Although this study provided critical information about potential plant invasions in different provinces of the ROK under current and future climatic conditions, our models were based only on bioclimatic variables, disregarding land use and land cover change, dispersal capacities, biotic interaction (e.g., facilitation and competition), and vectors driving species invasions, as described by Pysek and Richardson (2010) and Martin et al. (2013). This study is a part of ongoing research; we would consider using other variables, such as land use and land cover change, roads, foreign trade data involving dispersion capacities, and biotic interactions, to obtain more accurate prediction in the near future.

\section{Conclusions}

In this study, we predicted the current and future potential habitats for invasive plant species for which additional suitable areas are likely to be created in the different provinces due to climate change in the future. The continuous 
Table 6 Average and maximum invasive species expansion in different provinces of Korea

\begin{tabular}{|c|c|c|c|c|c|c|c|c|c|c|c|c|}
\hline \multirow[t]{3}{*}{ Province name } & \multicolumn{6}{|c|}{ RCP 4.5} & \multicolumn{6}{|c|}{ RCP 8.5} \\
\hline & \multicolumn{2}{|c|}{2030} & \multicolumn{2}{|l|}{2050} & \multicolumn{2}{|l|}{2080} & \multicolumn{2}{|l|}{2030} & \multicolumn{2}{|c|}{2050} & \multicolumn{2}{|c|}{2080} \\
\hline & Avg & Max & Avg & Max & Avg & Max & Avg & Max & Avg & Max & Avg & Max \\
\hline Gangwon & 1.28 & 5.00 & 1.97 & 9.00 & 5.09 & 10.00 & 2.74 & 10.00 & 2.75 & 10.00 & 5.76 & 11.00 \\
\hline Gyeonggi & 2.27 & 9.00 & 4.75 & 10.00 & 6.78 & 10.00 & 4.93 & 10.00 & 4.26 & 9.00 & 6.53 & 11.00 \\
\hline Gyeongsangnam & 3.97 & 10.00 & 5.19 & 11.00 & 6.07 & 11.00 & 4.79 & 10.00 & 4.24 & 10.00 & 4.94 & 10.00 \\
\hline Gyeongsangbuk & 1.85 & 9.00 & 1.17 & 8.00 & 4.59 & 11.00 & 1.51 & 10.00 & 1.92 & 10.00 & 4.48 & 11.00 \\
\hline Gwangju & 1.70 & 5.00 & 3.24 & 7.00 & 1.93 & 7.00 & 1.66 & 5.00 & 1.44 & 5.00 & 2.34 & 6.00 \\
\hline Daegu & 3.20 & 8.00 & 1.80 & 8.00 & 5.42 & 10.00 & 3.44 & 9.00 & 2.85 & 8.00 & 4.41 & 9.00 \\
\hline Daejeon & 2.69 & 6.00 & 2.89 & 7.00 & 5.12 & 9.00 & 3.29 & 7.00 & 3.00 & 6.00 & 3.50 & 8.00 \\
\hline Busan & 3.98 & 7.00 & 6.69 & 11.00 & 7.13 & 11.00 & 4.77 & 10.00 & 5.35 & 11.00 & 3.35 & 6.00 \\
\hline Seoul & 3.99 & 9.00 & 6.87 & 9.00 & 7.34 & 10.00 & 5.67 & 11.00 & 6.63 & 8.00 & 7.05 & 10.00 \\
\hline Sejong & 2.14 & 5.00 & 2.65 & 6.00 & 4.34 & 8.00 & 1.74 & 6.00 & 2.53 & 5.00 & 3.55 & 6.00 \\
\hline Ulsan & 4.77 & 9.00 & 4.96 & 9.00 & 5.50 & 10.00 & 4.54 & 10.00 & 4.80 & 11.00 & 3.64 & 7.00 \\
\hline Incheon & 2.62 & 7.00 & 3.25 & 7.00 & 5.41 & 10.00 & 2.82 & 8.00 & 2.63 & 6.00 & 5.52 & 9.00 \\
\hline Jeollanam & 2.33 & 8.00 & 3.95 & 11.00 & 3.37 & 11.00 & 3.32 & 10.00 & 2.85 & 9.00 & 3.64 & 10.00 \\
\hline Jeollabuk & 1.62 & 6.00 & 3.32 & 8.00 & 4.77 & 10.00 & 2.48 & 7.00 & 2.30 & 9.00 & 3.52 & 10.00 \\
\hline Jeju & 2.90 & 7.00 & 2.53 & 6.00 & 4.94 & 8.00 & 2.28 & 6.00 & 3.19 & 7.00 & 3.94 & 9.00 \\
\hline Chungcheongnam & 1.97 & 6.00 & 2.68 & 7.00 & 4.19 & 11.00 & 1.95 & 7.00 & 2.43 & 7.00 & 3.88 & 8.00 \\
\hline Chungcheongbuk & 1.54 & 8.00 & 1.67 & 8.00 & 6.62 & 10.00 & 3.61 & 9.00 & 2.54 & 8.00 & 5.23 & 10.00 \\
\hline
\end{tabular}

Avg average species richness, Max maximum species richness

increase in the climatically suitable habitats of invasive plant species has already caused adverse impacts on biodiversity, ecosystem services, food security, and livelihood in the ROK. The results of this study can be used as a precautionary note and might be helpful to develop policy in each province for the cost-effective management of invasive plant species. Additionally, our study will support the prevention and early detection of invasive plant species in their potentially suitable niches. Based on our study, we urge that it is necessary to perform early identification and eradication actions in all provinces, especially focusing on the western, southern, southeastern, and northern regions of ROK, including Jeollanam, Jeollabuk, Chungcheongnam, Daejeon, Gwangju, Gyeonggi, Seoul, and Incheon.

\section{Supplementary information}

Supplementary information accompanies this paper at https://doi.org/10. 1186/s41610-019-0134-3.

Additional file 1: Table S1. List of bioclimatic variables. Table S2. Spearman's correlation for variable selection.

Additional file 2: Figure S1. Potential distribution of Ambrosia artemisiifolia under RCP 4.5 and RCP 8.5 for the year 2030, 2050 and 2080. Figure S2. Potential distribution of Ambrosia trifida under RCP 4.5 and RCP 8.5 for the year 2030, 2050 and 2080. Figure S3. Potential distribution of Ageratina altissima under RCP 4.5 and RCP 8.5 for the year 2030, 2050 and 2080. Figure S4. Potential distribution of Paspalum distichum var. indutum under RCP 4.5 and RCP 8.5 for the year 2030, 2050 and 2080. Figure S5. Potential distribution of Paspalum distichum under
RCP 4.5 and RCP 8.5 for the year 2030, 2050 and 2080. Figure S6. Potential distribution of Solanum carolinense under RCP 4.5 and RCP 8.5 for the year 2030, 2050 and 2080. Figure S7. Potential distribution of Rumex acetosella under RCP 4.5 and RCP 8.5 for the year 2030, 2050 and 2080. Figure S8. Potential distribution of Sicyos angulatus under RCP 4.5 and RCP 8.5 for the year 2030, 2050 and 2080. Figure S9. Potential distribution of Hypochaeris radicata under RCP 4.5 and RCP 8.5 for the year 2030, 2050 and 2080. Figure S10. Potential distribution of Solidago altissima under RCP 4.5 and RCP 8.5 for the year 2030, 2050 and 2080. Figure S11. Potential distribution of Lactuca serriola under RCP 4.5 and RCP 8.5 for the year 2030, 2050 and 2080.

\section{Abbreviations}

AUC: Area under the curve; $\mathrm{CO}_{2}$ : Carbon dioxide; ENM: Ecological niche model; MaxEnt: Maximum entropy; RCP: Representative Concentration Pathways; ROC: Receiver operating characteristics; ROK: Republic of Korea; TSS: True Skill Statistic

\section{Authors' contributions}

PA analyzed the data, prepared the results, and wrote the manuscript. JYJ, HWK, and MSS helped with data analysis, PA surveyed the literature and helped in writing the manuscript, and CS designed the study and coordinated overall research. All authors read and approved the final manuscript.

\section{Funding}

This study was supported by Korea Environment Industry and Technology Institute (KEITI) through the "Climate Change Response Technology Project", funded by Korea Ministry of Environment (2014001310009). Therefore, authors are grateful to the project for providing the research fund.

\section{Availability of data and materials}

Not applicable.

Ethics approval and consent to participate Not applicable. 


\section{Consent for publication}

Not applicable.

\section{Competing interests}

The authors declare that they have no competing interests.

\section{Author details}

${ }^{1}$ National Institute of Ecology, 1210 Geumgang-ro, Maseo-myeon, Seocheon, Chungcheongnam 33657, Republic of Korea. ${ }^{2}$ Central Department of Botany, Tribhuvan University, Kathmandu, Nepal.

\section{Received: 9 August 2019 Accepted: 16 October 2019}

\section{Published online: 26 November 2019}

\section{References}

Adhikari P, Park S-M, Kim T-W, Lee J-W, Kim G-R, Han S-H, et al. Seasonal and altitudinal variation in roe deer (Capreolus pygargus tianschanicus) diet on Jeju Island, South Korea. J Asia-Pac Biodivers. 2016;9:422-8.

Adhikari P, Shin M-S, Jeon J-Y, Kim HW, Hong S, Seo C. Potential impact of climate change on the species richness of subalpine plant species in the mountain national parks of South Korea. J Ecol Environ. 2018;42:36. https:// doi.org/10.1186/s41610-018-0095-y.

Allouche $\mathrm{O}$, Tsoar A, Kadmon R. Assessing the accuracy of species distribution models: prevalence, kappa and the true skill statistic (TSS): assessing the accuracy of distribution models. J Appl Ecol. 2006:43:1223-32.

Bezeng BS, Morales-Castilla I, van der Bank M, Yessoufou K, Daru BH, Davies TJ. Climate change may reduce the spread of non-native species. Ecosphere. 2017:8:e01694.

Bradley BA, Blumenthal DM, Early R, Grosholz ED, Lawler JJ, Miller LP, et al. Global change, global trade, and the next wave of plant invasions; 2012. https://doi. org/10.1890/110145.

Bradley BA, Wilcove DS, Oppenheimer M. Climate change increases risk of plant invasion in the Eastern United States. Biol Invasions. 2010;12:1855-72.

Cho $\mathrm{KH}$, Lee $\mathrm{SH}$. Prediction of changes in the potential distribution of a waterfront alien plant, Paspalum distichum var. indutum, under climate change in the Korean Peninsula. Ecol Resil Infrastruct. 2015;2:206-15 [In Korean].

Cullen J, Knees SG, Cubey HS. The European garden flora: manual for the identification cultivated of plants in Europe, both out-of-doors and under glass. 2nd ed. Cambridge: Cambridge University Press; 2011.

Dullinger I, Wessely J, Bossdorf O, Dawson W, Essl F, Gattringer A, et al. Climate change will increase the naturalization risk from garden plants in Europe Glob Ecol Biogeogr. 2017:26:43-53.

Early R, Bradley BA, Dukes JS, Lawler JJ, Olden JD, Blumenthal DM, et al. Global threats from invasive alien species in the twenty-first century and national response capacities. Nat Commun. 2016;7. https://doi.org/10.1038/ ncomms 12485 .

Ehrenfeld JG. Effects of exotic plant invasions on soil nutrient cycling processes. Ecosystems. 2003;6:503-23.

Eminniyaz A, Qiu J, Tan D, Baskin CC, Baskin JM, Nowak RS. Dispersal mechanisms of the invasive alien plant species Buffalobur (Solanum rostratum) in cold desert sites of Northwest China. Weed Sci. 2013;61:557-63.

Guillera-Arroita G, Lahoz-Monfort JJ, Elith J, Gordon A, Kujala H, Lentini PE, et al. Is my species distribution model fit for purpose? Matching data and models to applications: matching distribution models to applications. Glob Ecol Biogeogr. 2015;24:276-92.

Hellmann JJ, Byers JE, Bierwagen BG, Dukes JS. Five potential consequences of climate change for invasive species. Conserv Biol. 2008;22:534-43.

IPCC. Intergovernmental panel on climate change. Summary for policymakers. In: Stocker TF, Qin D, Plattner GK, et al., editors. Climate change 2013: the physical science basis. Cambridge and New York: Contribution of Working Group I to the Fifth Assessment Report of the Intergovernmental Panel on Climate Change; 2013.

Jung SY, Lee JW, Shin HT, Shin SJ, Kim JB, An TI, et al. Invasive alien plants in South Korea. Pocheon: Korea National Arboretum, Sumeunkil Publishing Company; 2017.

Koo KA, Kong WS, Nibbelink NP, Hopkinson CS, Lee JH. Potential effects of climate change on the distribution of cold-tolerant evergreen broadleaved woody plants in the Korean Peninsula. PLoS One. 2015;10: e0134043.
Lamsal P, Kumar L, Aryal A, Atreya K. Invasive alien plant species dynamics in the Himalayan region under climate change. Ambio. 2018;47:697-710.

Lee SH, Cho KH, Lee WJ. Prediction of potential distributions of two invasive alien plants, Paspalum distichum and Ambrosia artemisiifolia, using species distribution model in Korean Peninsula. Ecol Resil Infrastruct. 2016:3:189-200 [In Korean].

Lenoir J, Gégout JC, Marquet PA, de Ruffray P, Brisse H. A significant upward shift in plant species optimum elevation during the 20th century. Science. 2008; 320:1768-71.

Loarie SR, Carter BE, Hayhoe K, McMahon S, Moe R, Knight CA, et al. Climate change and the future of California's endemic flora. PLoS One. 2008;3:e2502.

Lobo JM, Jiménez-Valverde A, Real R. AUC: a misleading measure of the performance of predictive distribution models. Glob Ecol Biogeogr. 2008; $17: 145-51$

Liu Y, Oduor AM, Zhang Z, Manea A, Tooth IM, Leishman, MR, Xu X, et al. Do invasive alien plants benefit more from global environmental change than native plants? Glob Chang Biol. 2017;23:3363-3370.

Manchester SJ, Bullock JM. The impacts of non-native species on UK biodiversity and the effectiveness of control. J Appl Ecol. 2000;37:845-64.

Manzoor SA, Griffiths G, lizuka K, Lukac M. Land cover and climate change may limit invasiveness of Rhododendron ponticum in Wales. Front Plant Sci. 2018;9. https://doi.org/10.3389/fpls.2018.00664.

Martin Y, Van Dyck H, Dendoncker N, Titeux N. Testing instead of assuming the importance of land use change scenarios to model species distributions under climate change: land use change scenarios in climate impact models. Glob Ecol Biogeogr. 2013;22:1204-16.

Ministry of Environment. The fifth national report to the convention on biological diversity. Ministry of Environment, Republic of Korea;2014.

Ministry of Environment. Climate change outlook. Ministry of Environment, Republic of Korea. 2019. http://eng.me.go.kr/eng/web/index.do?menuld=220. Accessed 23 Jul 2019.

Nam HK, Song YJ, Kwon SI, Eo J, Kim MH. Potential changes in the distribution of seven agricultural indicator plant species in response to climate change at agroecosystem in South Korea. KJEE. 2018;51:221-33 [In Korean].

National Institute of Ecology. Monitoring of invasive alien species designated by the act on the conservation and use of biological diversity (IV). Seocheongun: National Institute of Ecology; 2017.

National Institute of Ecology. Information of Korean alien species. Seocheon-gun: National Institute of Ecology; 2019. http://kias.nie.re.kr/home/main/main.do. Accessed 29 July 2019

National Institute of Environmental Research. The second and third national ecosystem survey: 1997-2012. Incheon: National Institute of Environmental Research; 2013. [In Korean]

Park YH, Kim JW. Climate change and ecosystem based management strategies of invasive alien species. Republic of Korea: Korea Environment Institute; 2015. [ln Korean]

Pearsons RG. Species ditsribution modeling for conservation educators and practitioners. Lessons Conservation. 2010;3:54-8.

Petitpierre B, McDougall K, Seipel T, Broennimann O, Guisan A, Kueffer C. Will climate change increase the risk of plant invasions into mountains? Ecol Appl. 2016. https://doi.org/10.1890/14-1871.

Phillips SJ, Anderson RP, Schapire RE. Maximum entropy modeling of species geographic distributions. Ecol Model. 2006;190:231-59.

Pysek P. Richardson DM. Invasive species environmental change and management and health. Ann Rev Environ Resour. 2010;35:25-55.

Park HC, Lim JC, Lee JH, Lee GG. Predicting the potential distributions of invasive species using the landsat imagery and Maxent: focused on "Ambrosia trifida L. var. trifida" in Korean demilitarized zone. J Korean Env Res Tech. 2017:20:1-12.

Ricciardi A. Invasive speceis. In: Robert AM, editor. Encyclopedia of Sustainability Science and Technology; 2013.

Robert JH, Steven P, John L et al (2017). Package'dismo'. https://cran.r project.org/ web/packages/dismo. Accessed 09 Sep 2019.

Ryu T-B, Kim M-J, Lee C-W, Kim D-K, Choi D-H, Lee H, et al. Distribution characteristic of invasive alien plants in Jeju Island. J Ecol Environ. 2017;41. https://doi.org/10.1186/s41610-017-0042-3.

Shabani F, Kumar L, Ahmadi M. Assessing accuracy methods of species distribution models: AUC, specificity, sensitivity and the True Skill Statistic. GJHSS-B. 2018;18(91):6-18 Print ISSN 0975-587X.

Shrestha UB, Shrestha BB. Climate change amplifies plant invasion hotspots in Nepal. Divers Distrib. 2019. https://doi.org/10.1111/ddi.12963. 
Swets J. Measuring the accuracy of diagnostic systems. Science. 1988;240 1285-93.

Thapa S, Chitale V, Rijal SJ, Bisht N, Shrestha BB. Understanding the dynamics in distribution of invasive alien plant species under predicted climate change in Western Himalaya. PLoS ONE. 2018;13:e0195752.

Thuiller W, Lavorel S, Araujo MB. Niche properties and geographical extent as predictors of species sensitivity to climate change. Glob Eco Biogeogr. 2005;14:347-57.

Tiedeken EJ, Stout JC. Insect-flower interaction network structure is resilient to a temporary pulse of floral resources from invasive Rhododendron ponticum. PLOS ONE. 2015:10:e0119733.

\section{Publisher's Note}

Springer Nature remains neutral with regard to jurisdictional claims in published maps and institutional affiliations.

Ready to submit your research? Choose BMC and benefit from:

- fast, convenient online submission

- thorough peer review by experienced researchers in your field

- rapid publication on acceptance

- support for research data, including large and complex data types

- gold Open Access which fosters wider collaboration and increased citations

- maximum visibility for your research: over $100 \mathrm{M}$ website views per year

At $B M C$, research is always in progress.

Learn more biomedcentral.com/submissions 